\title{
The Mechanical Sciences in Leonardo da Vinci's Work
}

\author{
Agamenon R. E. Oliveira \\ Polytechnic School of Rio de Janeiro, Federal University of Rio de Janeiro, Rio de Janeiro, Brazil \\ Email: agamenon.oliveira@globo.com
}

How to cite this paper: Oliveira, A. R. E. (2019). The Mechanical Sciences in Leonardo da Vinci's Work. Advances in Historical Studies, 8, 215-238.

https://doi.org/10.4236/ahs.2019.85016

Received: October 6, 2019

Accepted: December 7, 2019

Published: December 10, 2019

Copyright $\odot 2019$ by author(s) and Scientific Research Publishing Inc. This work is licensed under the Creative Commons Attribution International License (CC BY 4.0).

http://creativecommons.org/licenses/by/4.0/

\begin{abstract}
This paper is a tribute to the fifth centenary of Leonardo da Vinci's death. The prominent figure of Leonardo da Vinci (1452-1519) appeared during the so-called Quattrocento (fifteenth century) of the Italian Renaissance. His main famous contemporaries are: Sandro Botticeli (1445-1510), Rafael Sanzio (1483-1520), Michelangelo Buonarotti (1475-1564), and Niccolò Machiavelli (1469-1527). Florence had been a remarkable city since the previous century and was the political, economic, and cultural center of its region. Humanist and naturalist thoughts were relevant and a kind of driving force throughout this period, resulting in a vast development of the sciences, arts, and technology. In this paper, only Leonardo's production in the mechanical sciences will be presented, in both the theoretical field and applied mechanics, including designs and machine constructions even if unfinished.
\end{abstract}

\section{Keywords}

History of Mechanics, History of Machines and Mechanisms, Leonardo's Machines, History of Engineering

\section{Introduction}

In History of Sciences, the role of Leonardo da Vinci's work is of fundamental importance (Isaacson, 2017). On one hand, his multifaceted work encompasses several fields of knowledge becoming the basis of many types of studies. On the other hand, some of his activities are of an artistic (Clark, 2001) nature combined with diversified technological knowledge leading to developments in areas that had previously seemed unconnected, such as biological sciences (anatomy and physiology) and engineering sciences. In addition, after Leonardo had died the seventeenth century Scientific Revolution (Henry, 1998) began, transforming 
his scientific oeuvre in a kind of a bridge between the ancient sciences and modern science, characterized by the new scientific method represented by Copernicus (1473-1543), Kepler (1571-1630), Ticho Brahe (1546-1601), Descartes (1596-1650), Galileo (1564-1642), Newton (1642-1727), and Leibniz (1646-1716) (Koyré, 1973). Finally, Leonardo's integrated form of developing knowledge (theoretical, empirical, pictorial, etc.), using graphical expressions (Capra, 2008), led him to search for certain types of paradigms providing comparisons and analogies among different fields. These aspects of his work increase its importance in the context of rethinking epistemological questions related to our stage of science development characterized by automation, neurosciences, artificial intelligence, biotechnology, as well as nano-sciences and nanotechnologies. ${ }^{1}$

Because of the magnitude of Leonardo's work, a wide-ranging study in a single paper can only touch the surface of important questions and neglect aspects that we want to study here. Hence, in this paper we will look at the mechanical sciences in Leonardo's work, covering both theories as well as the machine sciences (Pedretti, 1999). With respect to theories, his ideas of motion and equilibrium will be presented in relation to Aristotelian physics (Leeuwen, 2016). These studies show important aspects about the paradigm ruptures caused by the seventeenth century Scientific Revolution that can be considered in a broad sense of continuity versus ruptures, a question that continues to attract the attention of many historians of sciences. Due to its historical importance Leonardo's theory of dry friction ${ }^{2}$ will be discussed, showing its pioneering nature before the work of Guillaume Amontons (1663-1705) and Charles Augustin Coulomb (Coulomb, 2002), which is omitted by the majority of historians of sciences. With respect to machine design, the book Leonardo's Machines, by Mario Taddei, Edoardo Zanin, and Domenico Laurenza is commented on.

\section{Biographical Note}

Leonardo da Vinci (Figure 1) was the illegitimate son of a Florentine notary called Ser Piero, with a young peasant called Caterina. He was born on 15 April 1452 in Vinci, Italy, very close to Florence. Immediately after his birth he was left in his father's care. He grew up in his father's house, receiving the same education as his original family based on a long tradition of painters and artists, one of the characteristics of Vinci (Bartlet, 2013). He received only a formal

${ }^{1}$ Much is discussed today about the changes involved in a new scientific paradigm. While in the seventeenth century, the publication of the Principia resulted in the predominance of the physical sciences centered on a new theory of motion and gravitation, in the nineteenth century there was a prominence of thermodynamics and quantum mechanics, and the theory of relativity in the twentieth century. Today, we have a new configuration in the sciences. Its own development, new technologies, computing, especially artificial intelligence, all raise new questions and new connections between previously unconnected and separate fields. Is a new epistemological synthesis possible with all these elements?

${ }^{2}$ In engineering when teaching friction at most the name Coulomb is mentioned because he speaks of dry friction or Coulomb friction. Amontons's name is never mentioned, much less Leonardo da Vinci's. For a more comprehensive study of Leonardo da Vinci's contribution to the study of friction, see: Leonardo da Vinci's studies of friction, written by Ian M. Hutchings, published in 2016 by Cambridge University, Department of Engineering, Institute for Manufacturing and widely accessible on the internet. 


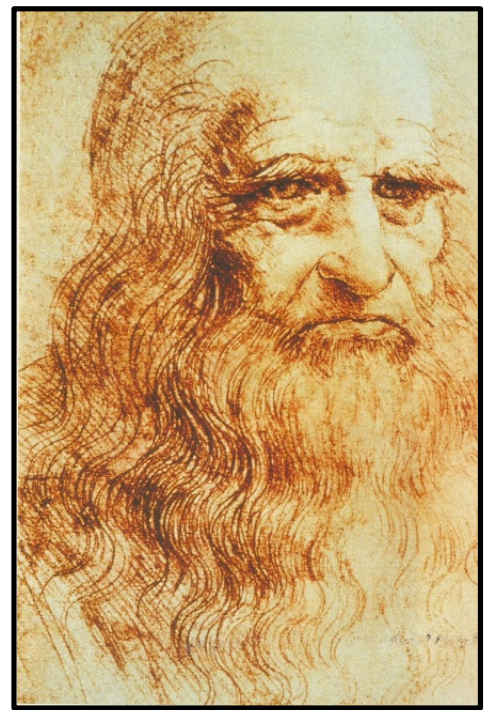

Figure 1. Self-portrait of Leonardo da Vinci (1452-1519).

education based in an "abacus school," a primary school that provided students with mathematical knowledge to be used in commerce (Grendler, 2002).

At the age of fifteen, his father sent him to work in Andrea del Verocchio's (1435-1488) workshop in Florence. Even at the beginning of his training, he demonstrated great talent in artistic activities, appearing in many pieces made by him in the period 1470-75. In fact, he overtook his master Verocchio in painting Christ's baptism where an angelic figure stands out in comparison to Verocchio's painting. He worked at the Verocchio workshop until 1477.

Verocchio's workshop looked like a store, as shoemakers and jewelers also did. On the first floor was the warehouse and diverse materials used for working, open to the street. Artisans and artists lived on the second floor, which was an accommodation space.

Looking for new challenges, Leonardo went to work in the Duchy of Milan in 1482, leaving Florence. His famous painting Adoration of the Magi belongs to this period. Leonardo lived for seventeen years in Milan, leaving the city after the fall of Duke Ludovico Sforza (1452-1508) in 1499. In this period, he reached the high point of his work, both scientific and artistic. He worked on painting and sculptures, but also designing weapons, buildings, and painting. Between 1485 and 1490, Leonardo produced many kinds of objects, such as flying machines, theoretical production including geometry and mechanics, civil construction, canals and architecture design. Also appearing in this period are military machines and submarines. Due to his engagement in many and different projects he left several of them unfinished. During these seventeen years he concluded only six works, including the famous painting The Last Supper and the Virgin of the Rocks.

Between 1490 and 1495, Leonardo began to carefully write down his observations and experiences in a kind of a booklet in which four main themes can be identified: painting, architecture, mechanical elements, and human anatomy. 
These studies and manuscripts were collected in codices and manuscripts, which are nowadays held in museums and private collections such as the one bought by Bill Gates for US $\$ 30$ million. For example, the Leicester Codex contains 72 pages with studies on geology and water resources. Another collection of manuscripts was reorganized under the name of the Atlanticus Codex, now in the Ambrosian Library in Milan (Figure 2). This collection has 2238 pages. The Arundel Codex, another collection, can be found in the British Library with 570 pages. The remainder of the manuscripts were dispersed, the bulk of which are now in France, England and Spain.

Coming back to Milan, after the fall of Ludovico Sforza in 1499, Leonardo looked for new patronage. Therefore, he travelled and worked for sixteen years throughout Italy with very few patrons. Among them was the famous Cesar Borgia. ${ }^{3}$ Leonardo worked as a military engineer for him, meeting Machiavelli, the famous author of The Prince.

Around 1503, Leonardo began to work on the Mona Lisa. From 1513 to 1516, he worked in Rome on many projects of the Pope's interest. He continued his studies of anatomy and physiology, but the Pope forbade him from dissecting bodies. His last and most generous patron was the French king Francis I, supporting him and his entourage in the Royal Palace in Amboise. In the final stage of his career, Leonardo also carried out some studies of the Virgin Mary, finishing the painting The Virgin, the Child and St. Anne. Leonardo died on 2 May 1519 in Cloux, France. According to some historians he died beside the King Francis I (1494-1547) who held his head with his arm. ${ }^{4}$

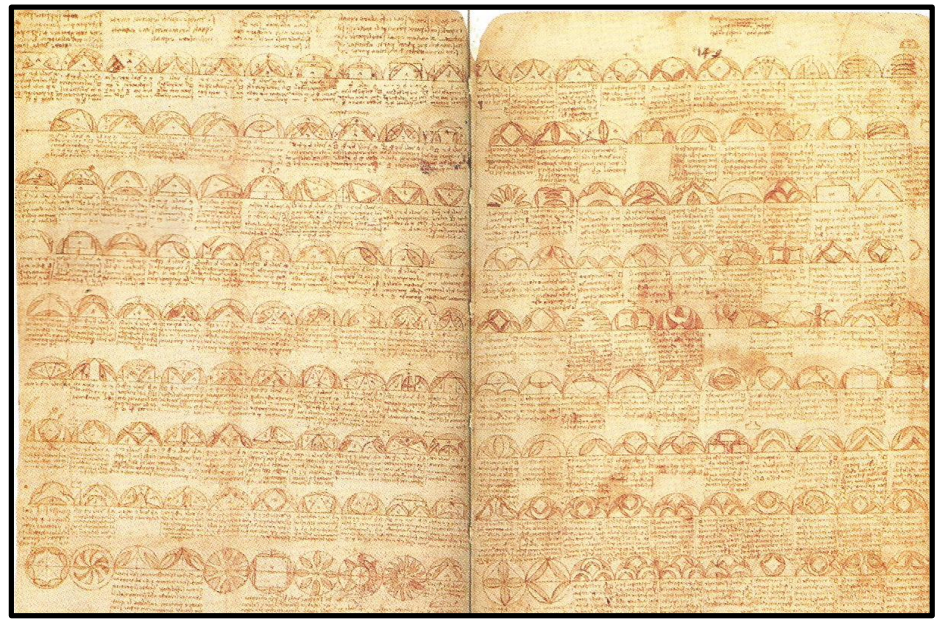

Figure 2. The Atlanticus Codex (Ambrosian Library).

${ }^{3}$ Caesar Borgia is known as one of the most bloodthirsty and merciless figures of all time. He was the son of Cardinal Rodrigo Borgia who would become Pope Alexander VI. He marched along-side King Louis XII in the invasion of Milan in 1499. The day after his arrival, they both went to see the Last Supper. This was the first time Borgia met Leonardo.

${ }^{4}$ Leonardo was buried in the church in Amboise Castle, but the current location of his body is unknown. The church was demolished in the early nineteenth century and after sixty years the ground was excavated and the bones that were found may belong to Leonardo. These remains were again buried in the chapel of Saint Hubert, next to the Castle, and the tombstone found there reads "presumed remains." 


\section{Education and Influences}

In the field of architecture (Burckhardt, 1985), Leonardo was heavily influenced by two prominent figures of the Italian Renaissance: Filipo Bruneleschi (1377-1446), famous for the cathedral dome of Florence, (King, 2010) who before becoming an architect had been a goldsmith. In addition, we know that he read some classical authors, such as Vitruvius (80 BCE-15 CE), specifically De Architecture. The second important influence was Bruneleschi's successor (Prager, 2004), the great theorist of linear perspective and famous Renaissance humanist Leon Alberti (1404-1472), who amplified and refined Bruneleschi's experiments on perspective (Tavernor, 1998). Around the age of thirty Alberti wrote his masterpiece: On Painting. Like Leonardo, Alberti was interested in almost all art and technology. Applied to the study of perspective the new methods improved painting and many other related disciplines, including cartography and scenography, with the latter being developed by Leonardo in many projects and scenarios, combining art and the mechanical design of devices with technology. One important Leonardo's biography was written by Giorgio Vasari: Lives of the Most Eminent Painters, Sculptors, and Architects. It was first published in 1550, and again in a revised and expanded form in 1568 (Vasari, 1991).

Moving on to our main field of interest, mechanical sciences, let us look at his most remarkable influences. According to Pierre Duhem (1861-1916), Leonardo read the book: Tratactus de ponderibus, which was published at the end of the fourteenth or at the beginning of the fifteenth century. It was written by Biagio Pelacani, also known as Blasius de Parma (1365-1416). He also published a Treatise on Weights in 1476. It was by means of his texts that statics in the thirteen and kinematics in the fourteenth century spread through the Italian school. ${ }^{5}$ Leonardo was also influenced by some older groups and schools. For example, the Giordano de Nemore school ${ }^{6}$ which was of special importance to the history of mechanics as it was a precursor of the principle of virtual works (Oliveira, 2006). His studies of the lever date from 1464.

Another important influence was Albert of Saxony (1320-1390). He was an original and vigorous thinker between the end of the fourteenth century and the beginning of the sixteenth century. He had a great and long influence on many thinkers from the end of the Middle Ages until the beginning of the Renaissance ${ }^{5}$ The so-called Italian school of mechanics, which flourished during the sixteenth century, belongs to many distinguished mathematicians and physicists. Their greatest importance is because they developed mechanical science in the period immediately preceding the 17 th century Scientific Revolution. They include: Nicolo Tartaglia, who was born in Brescia in the early 16th century and died in Venice in 1557; Jerome Cardan (1501-1576), who was directly influenced by Leonardo; Julius Caesar Scalinger, Benedict Pereira (1535-1610); Guido Ubaldo (1545-1607), famous for being one of Galileo's teachers; JB Villalpand (1552-1608); JB Benedetti (1530-1590); Giordano Bruno (1548-1600), well known for being burned alive in Rome, believing in the multiplicity of worlds, and finally Bernardino Baldi (1553-1617).

${ }^{6}$ Despite much research, the name Jordano or Giordano of Nemore remains a puzzle. His nationality is not known for sure, nor the period in which he lived. Three manuscripts on statics are attributed to him. Also associated with him are early works using the lever principle, from which later the principle of virtual Works (or velocities) derives. 
and was one of the most cited authors in this period. ${ }^{7}$ Among these were Jerome Cardan (1501-1576), Copernicus, Guido Ubaldo (1545-1607), and through the latter Galileo, obviously. He wrote Questions on Aristotelian Physics in Paris. As we know, he studied in the Sorbonne and also taught there between 1350 and 1361.

We own to Albert of Saxony a theory of weight which influenced the development of mechanics (Dugas, 1988). This theory was postulated in order to solve many difficulties of Aristotelian physics in discovering the natural place of Earth. According to Aristotelians if a body is placed in its natural place it remains in equilibrium. Otherwise it had the tendency to move back to its natural place. Within this discussion it was argued that the natural place of Earth was also the center of the universe, as postulated by the Peripatheticians.

As we know, Aristotle did not conceive anything similar to the idea of mass. In his physics all the resistance that appeared against a body in motion occurred from external sources. During its motion, if force disappeared the body would fall down immediately in a straight-line trajectory towards the ground. ${ }^{8}$ It is worth emphasizing that the concept of inertia, a key concept of mechanics, only arose of the seventeenth century Scientific Revolution.

\section{Leonardo and Mathematics}

In his studies on perspective, Leonardo systematically used geometry as a tool. Because of his extreme skill at drawing, as a logical consequence, it was also easy for him to develop methods of describing some common characteristics and similitudes, in different fields of natural sciences. This is different from starting with geometrical optics and building the basis for perspective studies (Grack, 2006). What drew Leonardo's attention to geometrical forms, unlike arithmetic and algebra, was the fact that geometry contains continuous quantities, whereas numbers are discontinuous quantities. Nowadays, using modern terminology we can say that Leonardo had a good familiarity with analog tools, in other words, he looked at nature trying to understand its transformations from the standpoint of continuous quantities. He did not use natural representations with quantities involving jumps and discontinuities. Based on this point of view some historians of sciences attributed to Leonardo a proximity with mathematics of continuous quantities, which in some cases led them to consider him a precursor of differential and integral calculus. Obviously, this is not the case, because similarly to

${ }^{7}$ As we have seen, Albert of Saxony, a physicist and astronomer, has had a very long influence on the history of science. We know that Leonardo absorbed many of his writings, although he also disagreed with many of the issues in them. In Pierre Duhem (1906) we can see these issues in detail. We also know that Albert of Saxony was a great commentator on Aristotle, Averroes and Alberto Magno.

${ }^{8}$ At the time of Albert of Saxony, in the fourteenth century, an innovative idea in mechanics appeared in the work of Nicole Oresme, which is the theory of impetus. This theory goes one step further in trying to resolve the contradictions that arose from the Aristotelian theory of motion by considering velocity associated with force. Impetus tried to explain the movement acquired by a body when it was launched and the trajectories described, before the question of inertia was finally solved. 
the concept of inertia, differential and integral calculus would only appear a century later during the Scientific Revolution of the seventeenth century. In addition, Leonardo was not a mathematician, unlike Descartes, Galileo, Newton and Leibniz, the founders of that Revolution.

Leonardo mathematical education was greatly influenced by the Milan court mathematician Luca Pacioli (1445-1517). Pacioli developed a new method for accounting studies called the double-match method. He also wrote a book on mathematics, written in Italian, instead of Latin, what was not usual at that time. This was published in Venice in 1494 (Figure 3).

It is no exaggeration to state that Leonardo not only learnt but was updated in mathematics by Pacioli, considered an excellent mathematician and teacher. Hence, Pacioli led Leonardo through the beauty and enchantments of Euclidian geometry. On the other hand, Leonardo illustrated Pacioli's book: Divina Proportione (Bertato, 2010) in which the role of proportions and mathematical ratios are analyzed in the context of architecture, arts, anatomy and mathematics. This narrow relationship between arts and science always drew Leonardo's attention.

The majority of Leonardo's drawings for Pacioli's book was finished in 1498, and basically are variations of the five known forms of the Platonic solids which have the same number of faces meeting at each vertex: pyramids, cubes, octahedrons, dodecahedrons and icosahedrons (Figure 4).

In his book, Pacioli also studied the Golden Ratio, which is an irrational number expressing one ratio appearing frequently in numerical series, geometry and the arts. This number is equivalent to 1.61803398 , approximately, having decimal places with no repetition, extending in a random form to infinity. Euclid (330 BCE-?) wrote about these proportions around 300 BCE and was the first mathematician to popularize this ratio. Leonardo wrote more two important geometrical studies. In the first Leonardo refers to the proportions of the human body which led him to the famous figure of Vitruvian man (1492). He used two figures from Vitruvius's book De Architetura (Figure 5), on the basis of which he drew his very popular image shown in Figure 6.

The second study refers to the Alhazen problem. Ibn al-Haytam (Alhazen) was a Muslim mathematician of either Persian or Arab origin, who lived around the year 1000 and is considered the founder of modern optics. The above-mentioned problem, described and solved by Ptolemy, is concerned with the reflection of light on reflecting surfaces a relevant problem related to painting (Figure 7).

Leonardo read copies of Euclide's manuscript of the Elements of Geometry, the first edition of which appeared in Venice in 1482. As mentioned before, he also read the work of his contemporaries such as Alberti, Pacioli, and Piero de la Francesca (1412-1492). It is thus possible to find some drawings and studies about the quadrature of the circle problem and studies of Pythagoras' theorem (582 a.C.-497 a.C.), as shown in Figure 8 (Leonardo da Vinci, 2010). 


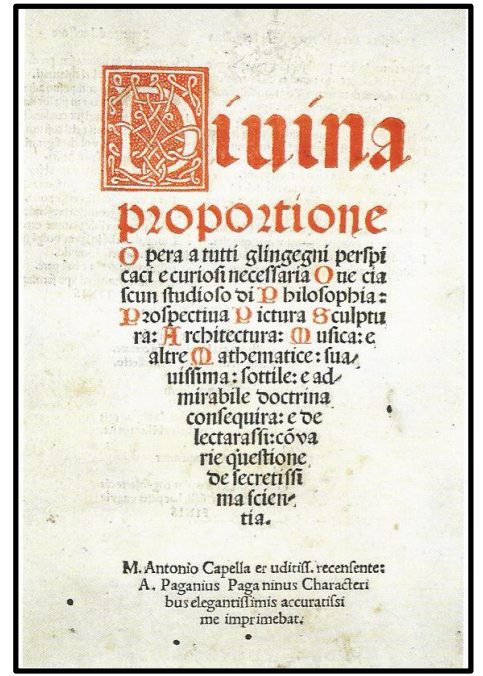

Figure 3. Frontispiece of Pacioli's book.

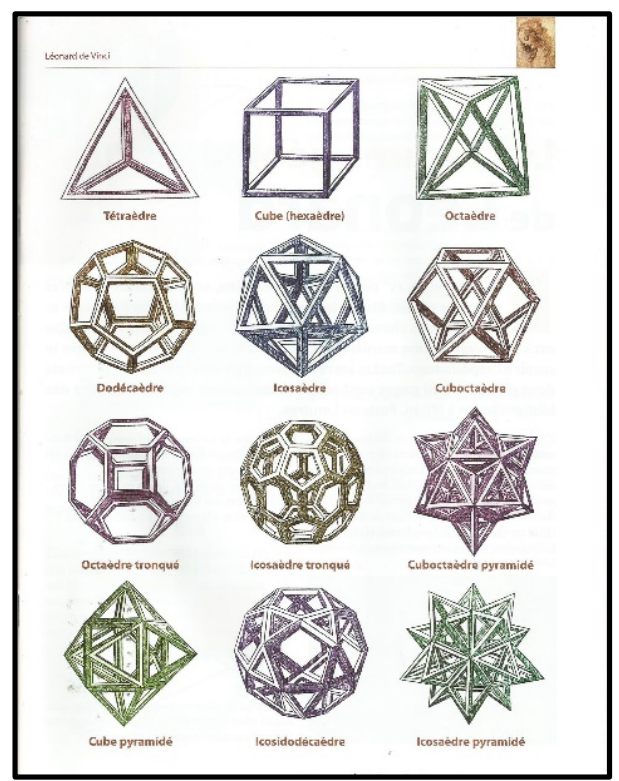

Figure 4. Leonardo's illustrations of Pacioli book.

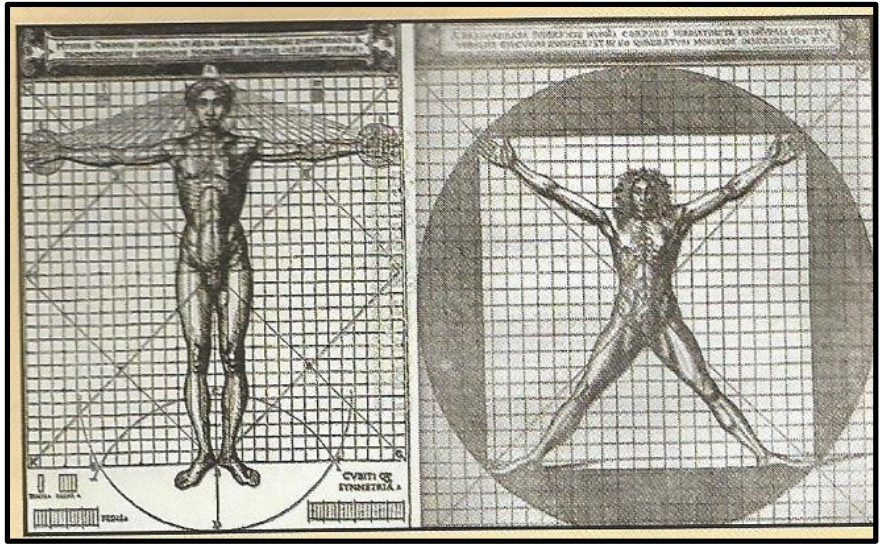

Figure 5. Figures from Vitruvius' book. 


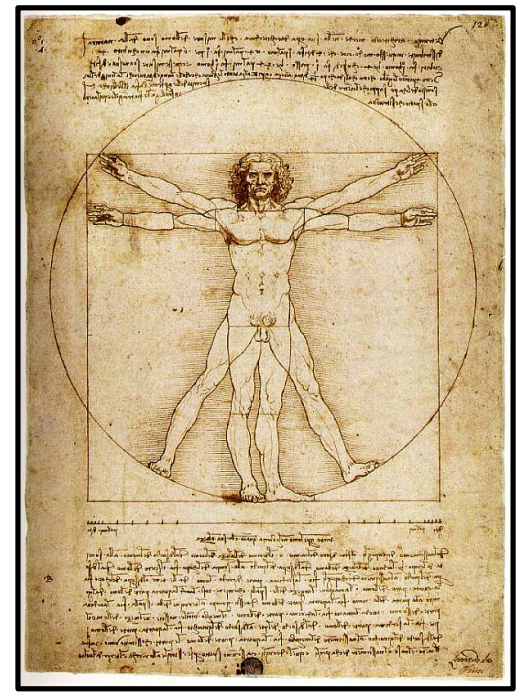

Figure 6. Vitruvian man.

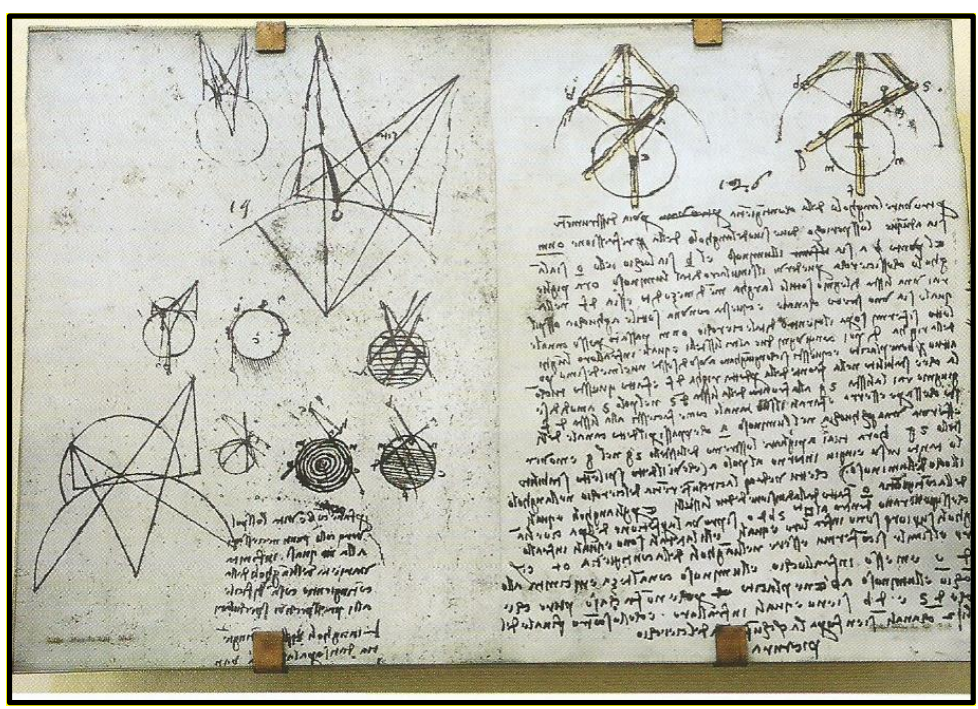

Figure 7. Alhazen's problem.

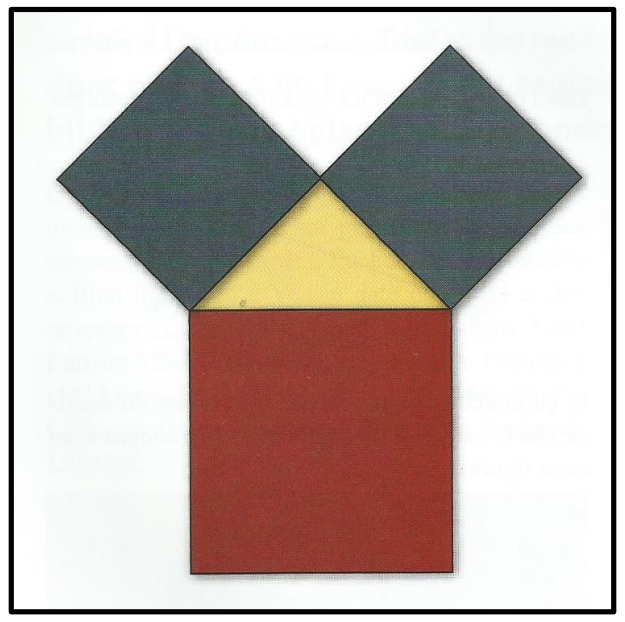

Figure 8. Demonstration of Pythagoras' theorem. 
Although the construction of the first modern calculating machine, called the Pascaline, is attributed to Blaise Pascal (1623-1662), in the Madrid Codex Leonardo da Vinci left a design of a mechanical calculator, 150 years before the Pascaline one. According to that Codex, the machine was built with a gear train consisting of numbered gears from 0 to 9 . It was designed that when one gear performed a complete turn the next gear turned one tooth. Thus, the machine was capable of performing the operations of addition and subtraction manipulating numbers which can reach 13 digits. In Figure 9 an outline of this calculator is shown. ${ }^{9}$

\section{Leonardo's Mechanical Theories}

Leonardo da Vinci, as we saw earlier, read and assimilated the ideas of many ancient philosophers, examined some of the problems they proposed, and more than once returned to them in different ways. His contribution to mechanics can be considered unique, original, and of great importance in studying the final passage to the Scientific Method established by the seventeenth century Scientific Revolution. Here we present his main contributions, starting with statics.

1) The concept of moment:

The idea of moment in Leonardo is associated with the equilibrium of a loaded lever, a problem studied extensively by Archimedes (287 B.C.-212 B.C.) and others, who contributed to the formulation of the principle of virtual velocities (Dugas, 1988). Together with the wedge, the gear, the pulley, the worm, and the inclined plane, these constitute the so-called simple machines of antiquity.

Assume the lever nb, in the vertical plane, (Figure 10), rotating around point $\mathrm{n}$. Leonardo established the following rule: The ratio of distance $\mathrm{mn}$ to distance $\mathrm{nb}$ is such that it is also the ratio weight in $d$ to weight in position $b$. This proposition accounts for the effect of the suspended weight in the lever in positions nd and nb. Leonardo calls the horizontal arm of the lever equivalent to the inclined

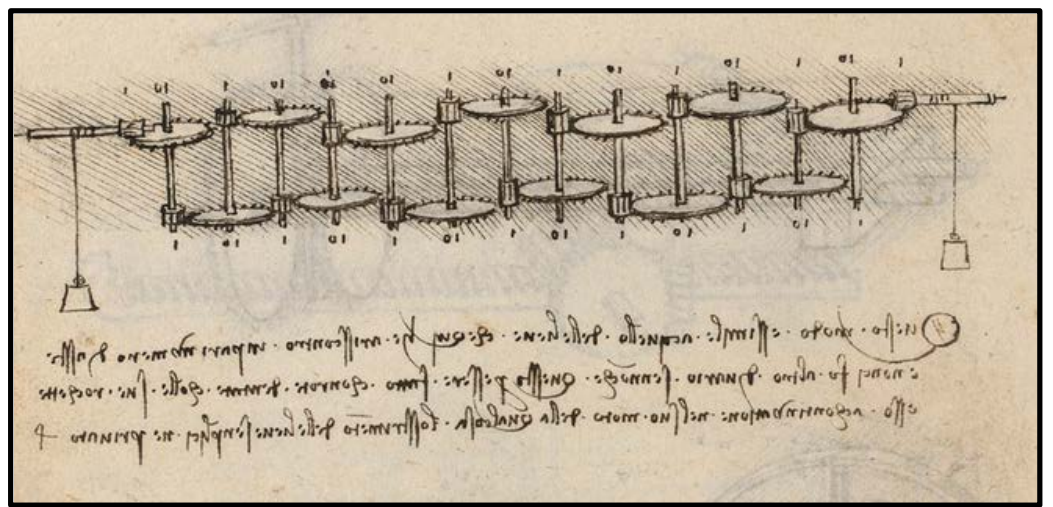

Figure 9. Leonardo da Vinci's calculating machine.

${ }^{9}$ We have already seen that Pierre Duhem found in Pascal many of the ideas Leonardo had already stated regarding hydrostatics, especially the famous Pascal principle. It may be a mere coincidence, but Pascal's calculating machine, Pascalina, only performs the addition and subtraction operations, just like the machine designed by Leonardo. It would be worth investigating if Pascal was aware of the machine designed by the latter. 


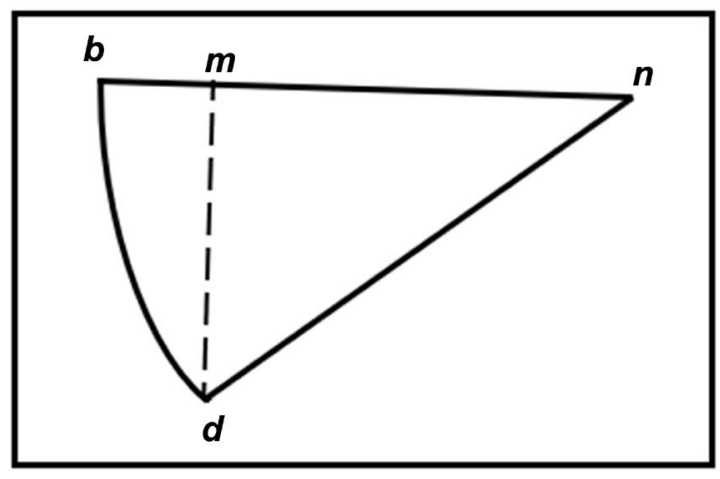

Figure 10. The lever equilibrium.

arm and by potential arm lever. Equating the ratios between the distances and the weights, one obtains the same result postulated by the principle of virtual velocities or virtual works which obviously is true for small angular displacements of the lever.

2) Body in an inclined plane:

A heavy spherical body will acquire a motion which will be fastest as long as its contact with the resting place is subsequently separated from the perpendicular through its centerline. The more $a b$ is shorter than ac, the body will fall more slowly along the line ac (than to o along the vertical $a b$ )... because if $p$ is the pole of the ball, the part $m$ which is away from $p$ will fall faster if there were no such small resistance provided by the counterbalance of the part o. And if this counter-equilibrium does not exist, the ball will fall along the line ac faster if o divided into $m$ more times. That is, if the part o divides into $m$ about one hundred times and the part o disappears through the rotation of the ball it will fall faster in $n$ by one hundredth of the ordinary time... If $p$ is the pole where the ball touchs the plane, the increasing of the distance between $n$ and $p$, faster will be the ball going down (Dugas, 1988) (Figure 11).

Looking at Figure 12, the problem studied by Leonardo was to understand for the system of three forces how the weight of the suspended body is distributed in $\mathrm{db}$ and $\mathrm{ab}$ strings. Initially he thought that the tensions in $\mathrm{db}$ and $\mathrm{ab}$ were distributed by the ratio of the lengths ea and de. This contradicts the parallelogram rule. However, in spite of this, Leonardo uses the following rule implicitly: With respect to a point taken in one of the component forces, the moment of the other component is equal to the total force with respect to the same point (Dugas, 1988).

This consideration above is very similar to the Pierre Varignon (1654-1722) theorem which establishes a relationship between the moment of the resulting force and the moment of component forces. ${ }^{10}$

\footnotetext{
${ }^{10}$ Pierre Varignon is one of the most important names in mathematics and mechanics in France. He is one of the main names responsible for the introduction of infinitesimal calculus in France and its application to mechanics. He was one of the first to algebraically formalize the terms representing velocity and acceleration of a particle. The theorem that bears his name was first discovered in the early seventeenth century by Simon Stevin and stated in its present form by Varignon in 1687: The momentum of the resulting force is equal to the sum of the moments of the components.
} 


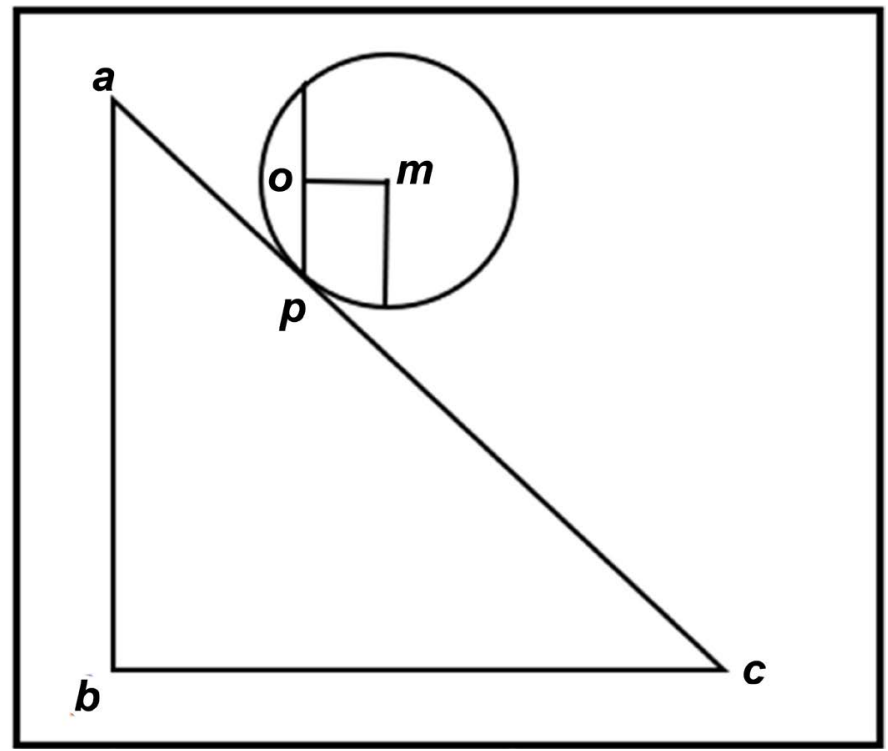

Figure 11. Body in an inclined plane (Dugas, 1988).

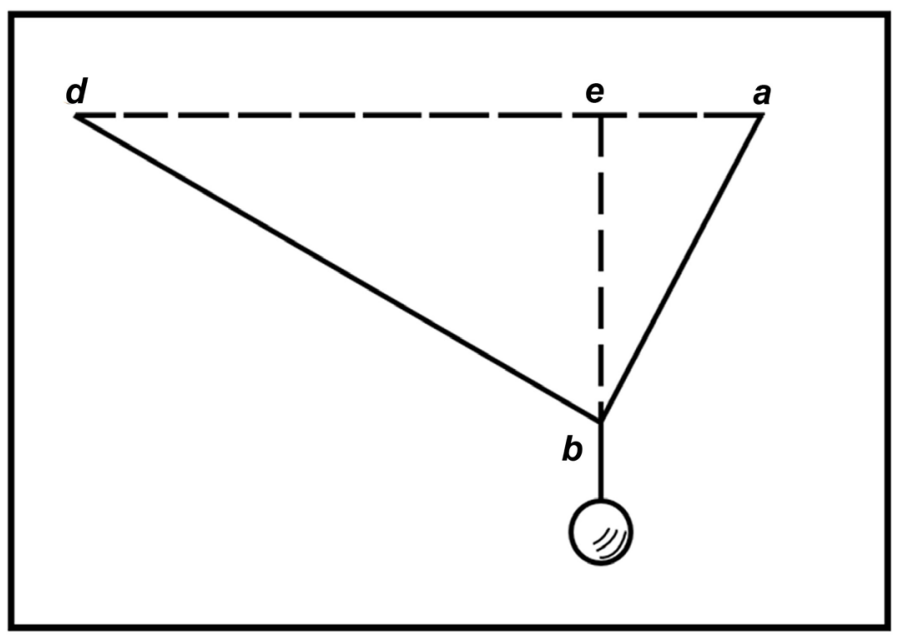

Figure 12. Three concurrent forces (Dugas 1988).

4) Dry friction:

In 2016, a paper published by Ian M. Hutchings, from the University of Cambridge, highlights the role of Leonardo da Vinci in the development of a science of friction. However, his contribution has not been widely recognized. Hutchings states: Based on a detailed study of Leonardo da Vincis notebooks, this review examines the development of his understanding of the laws of friction and their application... Diagrams which have been assumed to represent his experimental apparatus are misleading, but his work was undoubtedly based on experimental measurements and probably largely involved lubricated contacts. Although his work had no influence on the development of the subject over the succeeding centuries, Leonardo da Vinci holds a unique position as a pioneer in tribology (Hutchings, 2016).

Leonardo realized that what impedes perpetual motion is friction. Previously 
he reached these conclusions about this partial loss of motion studying the flight of birds and fish swimming. He made important experiments with heavy objects slipping on inclined planes. Consequently, he discovered important relations among the three parameters that are determinant in friction phenomenon: the weight of the object, the nature of surfaces in contact and the angle of inclination of the slipping. He also concluded that friction is independent of the contact area between the object and the surface where the slipping occurs.

These first laws of friction were rediscovered by Guillaume Amontons. $\mathrm{He}$ belonged to the founding group of scientists of the French Academy. However, the discovery of the modern science of friction is attributed to Coulomb (1736-1806) in his Théorie des Machines Simples which won him the Grand Prix from the French Academy in 1781. He investigated both static and dynamic friction of sliding surfaces, as well as friction in bending of ropes and rolling.

Leonardo carried out some experiments to measure the parameters involved in friction. Then, he analyzed what is known as the friction coefficient: the ratio between pressure (normal force), the surfaces in contact, and the tangential force (friction force). He obtained the value of 0.25 for the friction coefficient between two wood bodies, which is a good approximation, even today. Figure 13 shows the set up for these experiments.

Leonardo also discovered that the resistance between the surfaces in their relative motion decreases if we interpose a lubricant substance. Thus, after some experiments he indicated specific points where these substances should be applied in mechanical systems. He created the ball bearing (Figure 14) that can be used in some situations and in others a type of roller can separate the body and the ground to move heavy bodies.

Following these implementations of mechanical systems, a ball bearing was adapted to a screw jack (Figure 15). He realized that a ball bearing with three balls worked better than one with four because with three points we can pass one plane, while four balls produced instability.

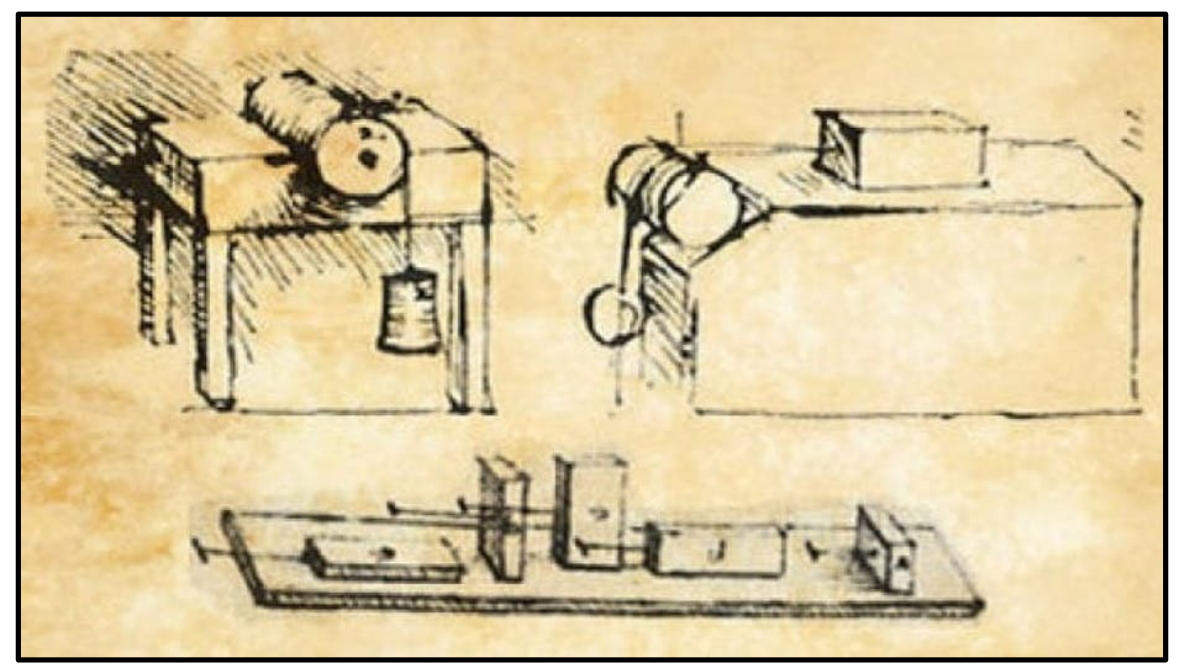

Figure 13. Experimental apparatus for friction measurements. 


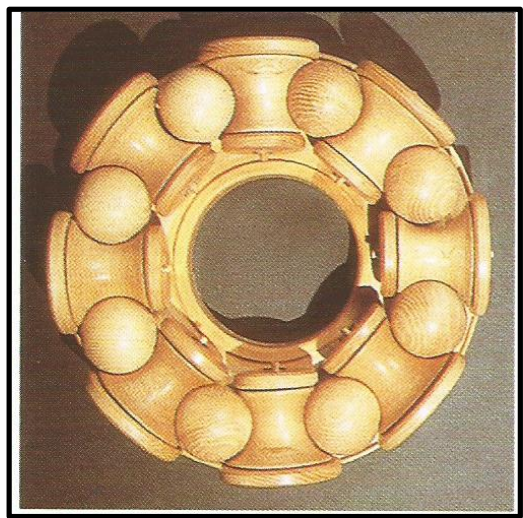

Figure 14. A ball bearing invented by Leonardo.

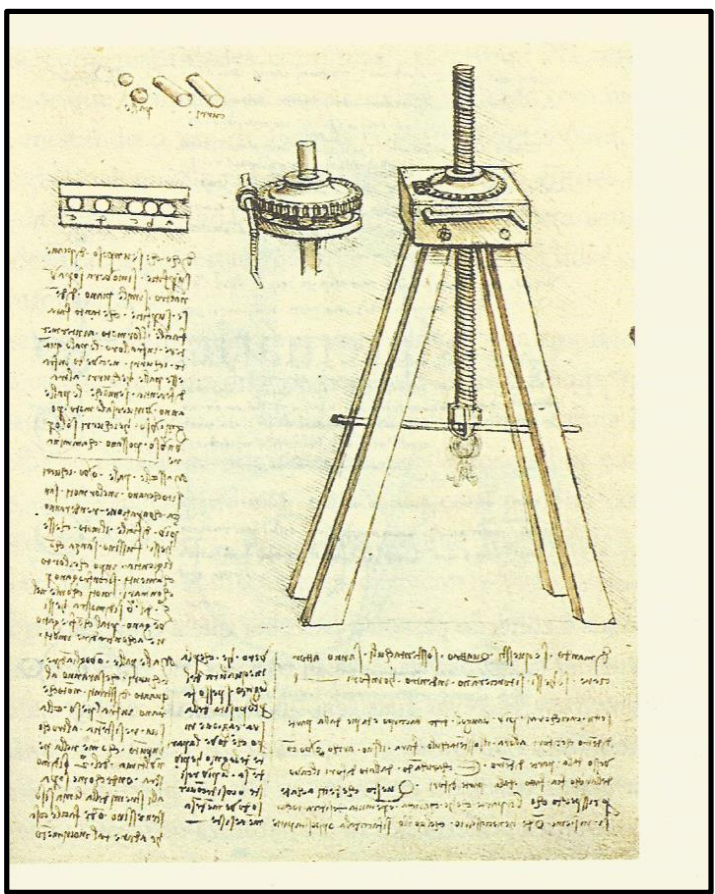

Figure 15. Screw jack with ball bearing.

\section{5) Strength of materials:}

Due to the publication of Galileo's Discorsi in 1638, in which he enunciated the two new sciences: mechanics (the science of motion) and strength of materials (the science of local motion), Galileo is considered the founder of the strength of materials. ${ }^{11}$ In addition, he created the conception of ultimate stress (force by ${ }^{11}$ On 25, 26 and 27 October 1988, COPPE (Coordination of Engineering Programs-Federal University of Rio de Janeiro) under the direction of Professor Luiz Pinguelli Rosa, held an international seminar celebrating the 350th anniversary of the publication of Galileo's Discorsi. The seminar was coordinated by Professor Lobo Carneiro, from the UFRJ Polytechnic School and a major international authority on Galileo's work. Attending the seminar were important figures from the history of science, such as Pierre Thuillier, other important historians and philosophers, as well as Galileo connoisseurs such as Ludovico Geymonat and Stillman Drake, amongst others. Professor Lobo Carneiro, since devoting himself to the study of Galileo's work, has become one of the best known voices in claiming for Galileo a fundamental importance as a pioneer of the Strength of Materials beyond Mechanical science. 
unit of area) analyzing a cylindrical bar loaded by simple tensile stress, as well as proposing that the strength of a bar is proportional to its cross section. Galileo also studied a rectangular bar with clamped-free extremities. He used the lever theory to predict the positions and the possible points of failure in the cross-sectional area.

However, Leonardo da Vinci's strength of materilas studies are little known. We should emphasize that they appeared a century before Galileo's Discorsi. Leonardo developed a theory of strength of areas which was found in a note in Notebook A of the Trivulzio Codex. Figure 16 shows the same load applied successively to a column and two different types of curved bars (arcs). Beside these sketches, Leonardo wrote: The straight line structure is the strongest. $\mathrm{He}$ continues: If one reduces by reasoning the vertical support to a simple straight line and the load to a heavy point, the resistance of this support will be infinite (Duhem, 1906).

In the same notebook one can also read: If one loads the support located in a perpendicular line, such that the center of this support be under the center of the weight, it will sink faster than bending because all of the weighted parts correspond to resistance points. It is possible that the support whose center is under the weight center supported by the perpendicular line can be folded, but it will press its base strongly (Duhem, 1906).

6) Hydrostatics:

The two fundamental principles of hydrostatics are Archimedes' principle, in which he developed in his treatise On Floating Bodies and Pascal's principle, set out in 1647-48. However, Pierre Duhem discusses the problems posed by hydrostatics in a series of Leonardo's writings in Del Moto and Misura delle Acqua, in which formulations very close to the Pascal's principle are presented in the passages where he analyses a hydraulic pump. Leonardo gives a very similar configuration to the famous principle, as follows:

A cylindrical pump body connects at the base to an equally cylindrical conduit, the water from the pump body (bottino) is pressed by a piston which carries a load (counterweight); at what height within the vertical conduit does water rise above its level in the pump body (Duhem, 1906)?

In general, Leonardo assumes that this load on the piston is replaced by a water cylinder with the same base and same weight as the counterweight. He uses

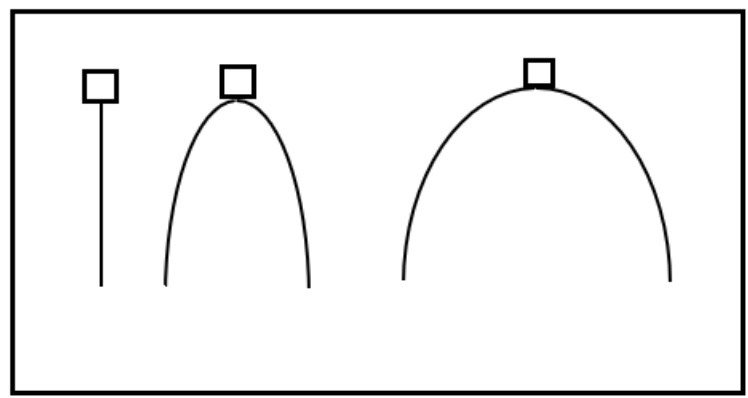

Figure 16. Leonardo's studies of strength of materials. 
this artifice constantly in statements that clearly show Pascal's principle, according to Duhem. In almost the entire part of this statement the piston has the same cross section as the pump body.

The weight of the water that any conduit raises above its level has such a proportion as that of the other water (equivalent to the counterweight) that the part that has the conduit section, the part of the pump body from which it discharges; the section of the water it pressure is supposed to be equal to that of the water it is pressing inside the pump body (Duhem, 1906).

Duhem considers this statement to be formally equal to Pascal's principle. In another section of our paper we will discuss the ways in which this knowledge was developed by Leonardo for Pascal.

Finally, Leonardo also derives from this statement some important consequences, such as the law according to which liquids of different densities overlap in communicating vessels.

7) Hydraulics:

Leonardo built an explanatory method to show how water could appear during the spring on the top of the mountains. He wrote: Necessarily the cause that keeps the blood on top, that is, in a man's head, is the same that keeps the water on the top of the mountains (Duhem, 1906). Leonardo sought this mechanism in processes involving heat. He stated: There are veins that allow blood to flow through the body of the Earth. The heat of the Earth distributed through this continuous body keeps the water high in these veins even at the sharpest heights (Duhem, 1906).

Albert of Saxony, in his commentary on the relevant parts of Aristotle's treatise, Meteors, had already involved the intervention of heat in this problem.

Leonardo also notes very well and makes a complete formulation of the law of currents: every movement of water of uniform width and surface is stronger in one place than in another, according to the fact that the water is shallower than in another. Leonardo also described the theory of hydraulic pumps in the manuscripts Del Moto and Misura delle'Acqua, in which through a suggestion, the principle of Pascal can be discovered (Duhem, 1906).

8) The fall of bodies:

Leonardo accepts many of Albert of Saxony's arguments about the free fall of bodies. ${ }^{12}$ He believes that motion (moto) is proportional to speed (velocitas) and, as a result, it was wrong to consider the law of distances.

He claims: About movement. a freely falling heavy body acquires one unit of motion in each unit of time; and a unit of speed for each unit of motion (Dugas, 1988).

We can say that in the first unit of time it acquires a unit of speed. In the second unit of time it will acquire two units of motion and two units of speed,

${ }^{12}$ The free fall of bodies was a central issue to be resolved in Aristotelian physics. According to this, heavier bodies hit the ground at higher speeds. Galileo's physics made it possible to abstract from the resistance of the environment and to the state that in a vacuum all bodies reach the ground at the same speed regardless of their weight. For the same height conditions from which it is abandoned and initial velocity there is an equality of conditions regardless of weight. 
and so on (Dugas, 1988).

9) Oblique shock laws:

Lagrange (1736-1813), in his Analytical Mechanics (1788), looks at how the problem of shock among hard particles was studied and explained the outcome of these interactions by analyzing quantities of motion. He points out that it was Descartes who first realized the principle behind this phenomenon. However, as he emphasizes, Descartes made a mistake in applying the principle, because he considered that the amount of absolute quantity motion was always conserved. After Lagrange, John Wallis (1616-1703) was the first to have a clear idea of the principle and used it to discover the laws of motion communication in the context of shocks between hard and elastic bodies, as presented in his Philosophical Transactions (1669), as well as in the third part of De Motu (1671).

Leonardo's study of the oblique shock of bodies resulting in its laws, is also found in the Codex Trivulzio, where one reads:

Every object that strikes another sturdy object bounces off it with an angle just like that on which percussion takes place (Duhem, 1906).

A similar study appears in the 12th Proposition of the third book:From the nature of shock, where it deals with a ball thrown against a wall (Duhem, 1906).

This is found in the notebook that is also part of the TrivulzioCodex: The percussion line and jump line are placed in the middle of equal angles (Duhem, 1906).

Every shock produced on an object results in a backward bounce at an angle equal to that of percussion (Duhem, 1906).

In Figure 17, We can see that if a ball is dropped at $C$, it returns back to the $B C$ line, because there is a restriction placed by the FG line; if we launch from line $B D$ it will return backward from line $D E$; and so the percussion line and the return line will make over the FG bulkhead an angle between two equal angles, as we see the angle $D$ between $M$ and $N($ Duhem, 1906).

It is important to note that Leonardo was already working with the concept of

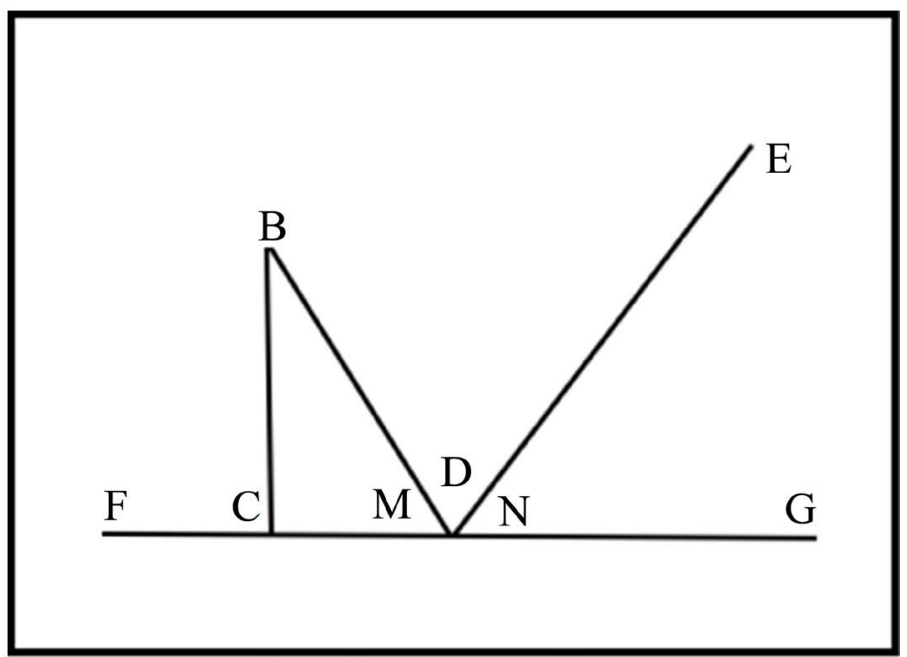

Figure 17. Oblique shock laws. 
constraints or links in mechanical systems, which would be completely expanded by D'Alembert (1717-1783) in his Treatise on Dynamics (1743), where, in this context he formulated the famous principle which bears his name.

10) The shape of the earth:

Leonardo wrote about this problem: All heavy bodies have the tendency to fall down and the things that rest at a given height do not remain at rest, but all of them after some time will fall. Thus, over time, the world becomes spherical and as a consequence completely covered by water (Dugas, 1988).

Without hesitation, Leonardo predicts that Earth will be uninhabitable. Another belief expressed by him is that the oceans do not press the contact surface with the Earth. Inversely he states: $A$ heavy body weighs more in a light environment. Thus, the Earth's surface that is surrounded by air is heavier than that under the water (Dugas, 1988).

11) Leonardo and the geocentric hypothesis:

According to Pierre Duhem: In 1508, when Copernicus began his meditations about the world system, during a period of 23 years (1507-1530), Leonardo da Vinci was convinced to reject the geocentric hypothesis and to declare that the Earth was neither at the center of the world nor at the center of the sun's circle (Duhem, 1906). ${ }^{13}$

Indeed, Leonardo has surely the merit to be called the great precursor of modern thought (Duhem, 1906).

\section{Leonardo's Machines}

Leonardo's great attraction to machines was due to his enormous interest in studying motion. By designing and building a machine he could reproduce existing motions that appeared in nature. It was also possible to build devices that mimicked living beings. Much like what he did with his dissected body designs, he also drew transparent views and exploded machine views to show how motion was transmitted through his elements and connections. Thus, he was able to establish relationships between concepts of anatomy and engineering.

It is also important to note that his perception of motion led to a body of ideas that anticipated much of what would later emerge as a core of the laws of motion developed by Galileo, Descartes, Newton, and Leibniz (1646-1716). Leonardo wrote: Every motion tends to keep, or rather, every moving body continues to move as long as the influence of the force that set it in motion is maintained upon It (Isaacson, 2017).

In his experiments with the inclined plane Galileo realized that a body abandoned on a inclined plane, and having another inclined plane on which it can ascend to the end of its descent course, tends to rise to about the same height that it was abandoned at. If the second inclined plane has its inclination approaching to horizontal line, the body tends to move infinitely along the hori-

${ }^{13}$ Pierre Duhem's statement that Da Vinci was already convinced that the earth was not the center of the world, is not accompanied by any reference, nor is it referred to in any study. It may be that Duhem formed this opinion using other sources not mentioned in the reference (Duhem, 1906). 
zontal line. The result of these experiments by Galileo practically anticipated the first law of motion prior to Newton's drafting of Principia. The above quotation from Leonardo prefigures the first law before Galileo, although it was enunciated by Newton in a context of force, that is, of its existence or not as an external action on a particle or body. The concept of force would thus only acquire a definite configuration within the theoretical framework of classical mechanics, with Newton himself.

Regarding the general aspects of motion, Leonardo investigated the possibility of perpetual or continuous motion. He began these studies in 1490, reaching the conclusion of its impossibility due to loss of motion due to obstacles, including friction, a matter also studied by him as previously presented in this paper.

Leonardo's interest in flying machines was due to the idea of building flying birds to make them appear in theatrical shows that were offered in courts. With this, and using his imagination, imaginary flying creatures also appeared.

There is currently no trace of the machines designed by Leonardo except his drawings in the various manuscripts and notebooks around the world. There is no trace of any three-dimensional model that may have been built during the design phase. In contrast, Figure 18 shows a work of paramount importance for the graphic and functional recovery of the machines designed by Leonardo da Vinci (Taddei \& Zanon, 2006). In 2006, Mario Taddei, Edoardo Zanon, and Domenico Laurenza, published Leonardo's Machines. Using writings and drawings left by Leonardo and modern graphical computation tools they were able to present all machines that Leonardo left, revaluing what they did best in terms of their graphical representations. With exploded machine views, assemblies, and diagrams associated with figures, the authors of the publication accomplished a kind of dream of Leonardo's, that is, they brought into a three-dimensional space a representation such as Leonardo once wished for.

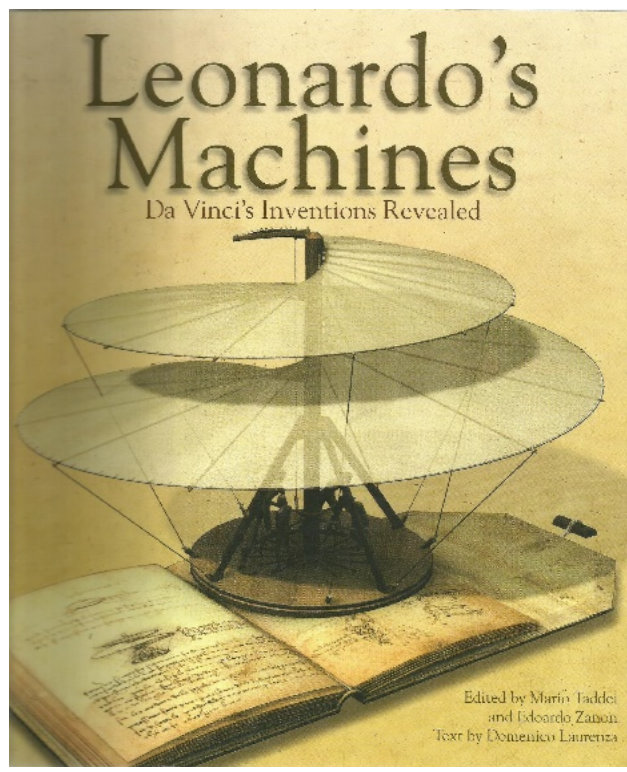

Figure 18. Leonardo's machines. 


\section{Leonardo's Scientific Method}

If we observe the development of the scientific method, from a strict point of view and what would be established following the Scientific Revolution, we can conclude that it developed over a period of almost 200 years, from the earliest studies of Copernicus in 1508 to the publication of Newton's Principia in 1687 (Newton, 1952). Leonardo died in 1519 when ideas of a new world system were beginning to thrive. He was born at a time of great social change, among which we can cite Guttenberg's invention of the printing press (around 1450), breaking the church's monopoly of the circulation of knowledge, and the Religious Reformation, whose fundamental milestone was the year 1517, when Martin Luther (1483-1546) nailed his 95 theses to the door of a church in Wittenberg, marking the beginning of the religious schism that in reality covered deep social transformations, especially in the power relations between social classes (Moments of History, 2018).

The crowning point of the development of a scientific method that was the publication of Newton's Principia. Its main feature was a virtuous relationship between theory and practice (experimental method), which began with the Copernican Revolution, followed by the theory of motion built on the abstraction and mathematization of space through Euclidean geometry, corroborated by the experiments performed by Galileo, proving and unifying the change in perspective postulated by Copernicus, Ticho Brahe, and Kepler for the solar system (Cohen, 1994). This method, also called hypothetical-deductive, is based on knowledge built on and supported by experimentation and allows the construction of a provisional theory until the emergence of new phenomena requires a partial or general reformulation of the theory. With this short remark, somewhat schematic and rather brief description of the current scientific method, we can also briefly analyze the scientific method used by Leonardo.

Leonardo da Vinci was not a mathematician, unlike most of those who later came to be at the forefront of the construction of the scientific method. Galileo, Descartes, Newton, and Leibniz were all great mathematicians who made specific and fundamental contributions to mathematics. Newton and Leibniz founded infinitesimal calculus (Oliveira, 2017), Descartes founded analytical geometry, and Galileo, professor of mathematics, created a geometry of motion (kinematics) studying experimentally the uniform motion, the uniformly accelerated and projectile motion, enunciating its laws. Leonardo had maths classes with Lucas Pacioli, as we described previously. However, his relationship with mathematics was mainly based on geometry, due to his great interest in studying the laws of linear perspective, a repository of fundamental knowledge for painting. Galileo's abstraction of space using Euclidean space and introducing the time parameter was fundamental for obtaining the laws of motion, which Leonardo would also do (abstraction), but time is replaced by a succession of drawings, as if each represents a certain instant. Formerly, the movies were constructed as a succession of strips of pictures slightly modified drawings representing the successive 
instants. Using this situation for a comparison its dynamics were graphically represented by Leonardo and algebraically by Galileo. This difference is absolutely fundamental in the ability to generalize and to predict subsequent moments as they obeyed a law founded on experimentation.

Regarding experimentation, Walter Isaacson, one of Leonardo's biographers, points out that in 1490 he wrote a discourse on how to be an "illiterate man" and a "disciple of experience," criticizing those who preferred to cite the knowledge of the ancients rather than instead of making his own observations about natural phenomena. An observer and experimentalist of natural phenomena, Leonardo was neither dedicated nor trained to deal with abstract concepts. Still according to Isaacson, he wrote:

My intention is to consult experience first and then, using reasoning, to demonstrate why such experience occurs in this way (Isaacson, 2017). He also said, according to Isaacson: Although nature begins in the cause and ends in the experience, we must follow the opposite path, that is, to begin with the experience to investigate the cause (Isaacson, 2017). Perhaps the physicist Leopold Infeld (1898-1968), has summarized perfectly Leonardo's closeness with the scientific method of modern science, but also the difficulties to achieve it when he said: We see Leonardo in a dramatic attempt to recognize that the theory is valuable as the experiment (Isaacson, 2017).

Finally, as Leonardo in several other scientific fields, including anatomy and physiology, it is important to emphasize his pursuits to identify patterns and similarities in various fields, and its constant use in their analysis. His predilection for spirals and swirls or vortices is well known, a pattern that appeared in both the flowing water or in the hair of various human figures appearing in his painting. The synthesis between science, art, and technology remains a hallmark of Leonardo's scientific method.

\section{Leonardo's Inheritance for the Modern Sciences}

First, our assessment of Leonardo da Vinci's importance for modern science is limited to the importance that mechanics as a theory had for the development of science in general. This is because in our article we restricted ourselves to his contribution to the mechanical sciences and, obviously, his contribution to other scientific fields is enormous. In addition, because of his importance for mechanical technologies such as the design and construction of machines and mechanical devices, this assessment would also have to be made, at least in relation to its prospective aspects. Given the scope of this paper, only some comments in this direction will be made. The technological aspects of Leonardo's work will continue to be an open question and a challenge to researchers of his work.

Even a cursory analysis of Leonardo's contribution to the mechanical sciences shows that he kept abreast of the mechanical theories that came from Aristotle, Archimedes, and the other philosophers and scientists who developed them in the preceding centuries. Studies of the lever using the moment concept, bodies 
in inclined planes, balance studies, force composition studies, friction investigations and others, would be very useful for the development of mechanics, notably for some authors, such as Simon Stevin (1548-1620), Jerome Cardan and Jean-Baptiste Benedetti (1530-1590), among many others. This knowledge was aligned with and strengthened a formidable flow that led directly to the Scientific Revolution of the seventeenth century (Cohen, 1985).

In 1797, the physicist Giovanni Battista Venturi (1746-1822) announced that some essential laws of modern mechanics were found in Leonardo da Vinci's manuscripts. The surprise of many mathematicians and physicists was great. Since Leonardo had lived almost a century before Galileo, there is unsubstantiated speculation about a much greater impetus of knowledge of mechanics as if his manuscripts had been circulated shortly after his death in 1519. It is quite plausible that Leonardo's ideas recorded in his notebooks exerted a significant influence on sixteenth century scientific thought, despite the loss and dispersal of much of his writing. Historians of science consider that Cardan's static derives largely from Leonardo's statics, while the Mechanical Exercises by Bernardino Baldi (1553-1617) was quite enriched by Da Vinci's ideas.

With respect to the Pascal principle, as we mentioned earlier, we can identify Marin Mersenne (1588-1648) as the link between Da Vinci and Blaise Pascal. There is no doubt that Pascal read the Physico-Mathematic Cogitata of Mersenne on the equilibrium of fluids. With Mersenne as an intermediary, Pascal came to know Stevin's findings; he was in turn influenced by Benedetti (1530-1590), which means ultimately an indirect influence of Da Vinci's ideas.

Finally, still in the field of fluid mechanics, a path can be established between Galileo and Leonardo da Vinci through the Benedictine Benedetto Castelli (1578-1643), who was Galileo's disciple and friend. Castelli also had a direct influence on the formation of two famous Galilean disciples: Bonaventura Cavalieri (1598-1647) and Evangelista Torricelli (1608-1647).

It was to Castelli that Galileo, already blind, sick and reclusive in his hometown of Arcetri, sent his last thoughts on dynamics. He was also the one who appointed Galileo to replace him as professor of mathematics at the University of Pisa. Thus, there was an intense exchange of ideas between the two, and both maintained a long correspondence. It is very likely that Castelli knew of Leonardo da Vinci's research on fluids, and so Galileo also did.

Let us look at the facts. In 1628 Castelli published in Rome the first edition of his celebrated treatise on fluids, called Delle misure dell acqua correnti. In it, one of Leonardo da Vinci's essential ideas appears, as follows: All sections of the same watercourse allow the same amount of water to pass at the same time; the water velocity that crosses a section is in inverse ratio of the area of this section (Duhem, 1906).

\section{Final Remarks and Conclusion}

As we commented earlier, we will conclude with some remarks about Leonardo's 
indirect contribution to modern science via technological production. It is well known that science and technology have a very complex relationship and interaction. Even nowadays, when it seems that the production of technology is increasingly dependent on scientific development, certain scientific theories are sometimes decades waiting for technological development to provide the means for their proof (Oliveira, 2013).

In the case of the production of technology by Leonardo, we are referring mainly to machine design and the manufacture of devices. In relation to this, his fertility and imagination, creativity, and technical knowledge are quite intriguing and very impressive. Vasari in his famous book (Vasari, 1991) describes the technological aspects of Leonardo's machine designs, as follows: He made designs of flour-mills, and engines, which might be driven by the force of water and since he wished that his profession should be painting, he studied much in drawing after nature, and sometimes in making models of figures in clay, over which he would lay soft pieces of cloth dipped in clay, and then set himself patiently to draw them on a certain kind of very fine Rheims cloth or prepared linen ...

A huge amount of these machines already prefigured a modernity that in the sixteenth century was still be far from occurring. His war machines, submarines, assault cars, cannons, machine guns, flying screw (ancestor of the helicopter), many machines for dredging, swing bridges, as well as very instructive recommendations about three dozen machines with the most varied applications, including for scenography and theater plays. Besides all of this, Leonardo also designed the necessary devices for their manufacture and assembly, making a remarkable contribution to engineering sciences in their diverse modes: civil, mechanical, metallurgy, shipbuilding, and even aircraft. No less important for engineering is its design of a mechanical calculating machine (Garfinkel \& Grunspan, 2018) placing it as a precursor of the calculating machines designed by Pascal, Leibniz, and Charles Babbage (1791-1871), raising it to the condition of a surprising modernity, the modernity of computer engineering.

\section{Conflicts of Interest}

The author declares no conflicts of interest regarding the publication of this paper.

\section{References}

Bartlet, K. R. (2013). A Short History of the Italian Renaissance. Toronto: University of Toronto Press.

Bertato, F. M. (2010). The "De Divine Proportione”(Vol. 56). CLE Collection.

Burckhardt, J. (1985). The Architecture of the Italian Renaissance. Chicago, IL: The University of Chicago Press.

Capra, F. (2008). The Botany of Leonardo da Vinci. S. Paulo: Thought-Publishing Cultrix Ltda.

Clark, K. (2001). Leonardo da Vinci. Rio de Janeiro: Publishing House. 
Cohen, H. F. (1994). The Scientific Revolution. The Historiographical Inquiry. Chicago, IL: The University of Chicago Press Chicago.

Cohen, I. B. (1985). Revolution in Science. Cambridge, MA: The Belknap Press of the Harvard University Press.

Coulomb, C. A. (2002). Theory of Simple Machines. Paris: Librairie Scientifique and Technique Al-Bert Blanchard.

da Vinci, L. (2010). Les Éditions du Kangouru. Paris.

Dugas, R. (1988). A History of Mechanics. New York: Dover Publications Inc.

Duhem, P. (1906). Etudes sur Leonardo da Vinci. Paris: Librairie Scientifique A. herman.

Garfinkel, S. L., \& Grunspan, R. H. (2018). The Computer Book. London: Sterling Publishings Co., Inc.

Grack, R. K. (2006). Leonardo da Vinci: Artist, Inventor and Renaissance Man. New York: Chelsea House Publishers.

Grendler, P. F. (2002). The Universities of the Italian Renaissance. London: The John Hopkins University Press.

Henry, J. (1998). The Scientific Revolution and the Origins of Modern Science. Rio de Janeiro: Jorge Zahar Editor.

Hutchings, I. M. (2016). Leonardo da Vinci's Studies of Friction. Cambridge, UK: University of Cambridge.

Isaacson, W. (2017). Leonardo da Vinci. Walking, Rio de Janeiro: Publisher Intrinsic Ltda.

King, R. (2010). Brune Lleschi’s Dome. New York: Vintage Books.

Koyré, A. (1973). The Astronomical Revolution. New York: Dover Publications, Inc.

Moments of History (2018). Protestant Reformation.

Newton, I. (1952). Mathematical Principles of Natural Philosophy. Chicago, IL: The University of Chicago Press.

Oliveira, A. R. E. (2006). History of the Principle of Virtual Works. IFToMM Workshops Lectures. Ithaca, NY: Cornell University.

Oliveira, A. R. E. (2013). A History of the Work Concept: From Physics to Economics. London: Springer.

Oliveira, A. R. E. (2017). Leibniz and the Sciences of Engineering. In R. Pisano, M. Fichant, P. Bussoti, \& A. R. E. Oliveira (Eds.), The Dia-Logue between Sciences, Philosophy and Engineering. New Historical and Epistemological Insights. Homage to Gottfried W. Leibniz 1646-1716 (pp. 287-308). London: College Publications.

Pedretti, C. (1999). Leonardo: The Machines. Florence: Giunti Gruppo Editoriale.

Prager, F. D., \& Soaglia, G. (2004). Brunelleschi Studies of His Technology and Inventions (Dover ed., pp. 287-308). London: College Publications.

Taddei, M., \& Zanon, E. (2006). Leonardo's Machines. Cincinnati, OH: David and Charles Book.

Tavernor, R. (1998). On Alberti and the Art of Building. New Haven, CT: Yale University Press.

Vasari, G. (1991). The Lives of the Most Eminent Painters, Sculptors, and Architects, Oxford World's Classics. 